\title{
Influencing Factors For Employees' Usage Intention of Internal Social Media Communication Technologies
}

\author{
Kristen Werling
}

\begin{abstract}
This study explores motivating and hindering factors for internal social media usage in organizations using the Theory of Planned Behavior. Organizational communication quality was considered as a unique moderating factor between social norms and usage intention. This qualitative study consists of 16 individual interviewees from six different organizations. Findings revealed that motivating factors included improvements to: organizational processes, knowledge management, and communication. Hindering factors included a lack of information concerning the personal benefits. It would seem that the better the communication quality is, the more the perceived social norms of usage is supported and thereby the usage intention.
\end{abstract}

Index Terms - Theory of Planned Behavior; internal social media; organizational communication quality; communication technologies

\section{INTRODUCTION}

Social media has become not only a useful, but an essential part of our everyday lives. In the Global Web Index's Social report from 2018, they found that 98 percent of online consumers are social media users [11]. More and more, social media is being identified as a beneficial communication tool to connect with people, organize arrangements, and voice opinions [6]. As the benefits of social media become more and more realized in our private lives, more are beginning to see potential benefits in organizations' internal communications and work processes [3]. Given this, this paper focuses on employees' intention to use internal social media tools within organizations.

Traditionally, internal business communication has consisted of mainly top down communication at the executive level through business newsletters, business television, emails, and annual company result meetings, which communicate essential business performance information, strategic goals and objectives, as well as current happenings within an organization $[28,41]$. While these mediums convey important information for employees, it is not the only form of internal business communication that takes place. Middle management communication usually occurs through emails, team meetings, and individual meetings with direct reports. At this level, business communication becomes increasingly interactive where employees have the opportunity and feel that they can ask questions and provide input on topics at hand [27, 41]. Finally, subordinate level communication entails: emails, brainstorming and progress meetings, telephone and video conferences, lunch and grapevine gossip and is often used by employees [13, 17, 33, 41]. While these communication mediums are irreplaceable and a necessity for

Published on March 21, 2020

Kristen Werling, Institute for Communication Psychology and Media Education, University of Koblenz-Landau, Germany.

(e-mail: werling@uni-landau.de) organizations to operate and for employees to successfully complete their tasks, it is important to anticipate what new communication mediums the future will bring for internal business communication and for the internal stakeholders that use them. When considering the past with the adoption of email within organizations, it was perhaps difficult for some to imagine the success and acceptance that email would hold. The convenience and speed that email brought to business was revolutionary, and it has now become a standard form of communication in our society. It is plausible that the use of social media tools within the organization might bring the same effects and advantages that email once did for business communication. While previous research has primarily focused on people's perceptions and usage of social media for external organizational communication $[10,26,43]$ or on the potential advantages that internal social media can bring to organizations [24, 40,44], this exploratory study seeks to identify potential motivating and hindering factors for internal social media usage from the employees' perspective by looking at: the usage intention of internal social media, the perceived attitudes and social norms towards internal social media usage, the perceived internal social media usage ability, and the perceived organizational communication quality among key internal stakeholders. Therefore, first internal social media will be defined. Then factors determining internal social media usage intention will be addressed. Finally, what influence organizational communication quality could have will be discussed.

\section{A. Internal Social Media}

Social media has become a household term. It is everywhere we look, from the news media to advertising for consumers to 'like' something. Not just younger generations, but also older generations are now becoming major user groups [30]. Furthermore, social media communication is transforming how organizations communicate with customers: "Traditional one-way communication in marketing has been transformed into a multi-dimensional two-way peer-to-peer communication reality. This new marketing communication reality presents new challenges and opportunities for companies as purchase decisions are increasingly influenced by social media interactions." $[15, \mathrm{p}$. 343]. This new interactive, two-way communication and how organizations deal with it is just one example of the challenges that organizations are facing in the new digital age. Furthermore, social media has certainly changed how society views the way and speed of communicating information $[31,38]$. As a society, we expect to be able to easily connect with others and be immediately informed of 
the latest happenings in real time. This desire to 'connect with others' and 'always be informed' has had such a strong impact on most people's private lives, that it is reasonable to think that people would expect this speed of information exchange in their professional lives as well.

In order to adapt to this new phenomena, companies have started taking steps to implement internal social media tools which allow employees access to and exchange the latest information, as well as to connect with each other on a much broader basis than emails alone [2, 27, 28]. Depending on the extent of what information is needed and should be exchanged, organizations are implementing everything from wikis and blogs to complete social networks and project management platforms. For purposes of this study and based on the above literature, internal social media has been defined as any interactive tool or platform, within a secured network, behind an organization's firewall used to exchange and provide information and/or connect with other employees. Now that it is clear what internal social media is, it is important to understand what factors might influence employees' motivation and intention to use internal social media

\section{B. Individual Driving and Hindering Factors}

When organizations invest the time and money into implementing something new, they hope or expect that employees will use it. This is no different in regards to internal social media. If organizations implement these new technologies for employees, then it is wished that employees use them. This, however, is not always the case, which can result in wasted resources. Therefore, organizations must first understand not only what driving factors can possibly influence employees to use internal social media, but also what factors could possibly hinder employees in using these technologies. The Theory of Planned Behavior (TPB) [1], is a highly accepted theory used across various disciplines to observe such relationships and determine factors which can possibly support or hinder certain behaviors. The TPB is used as a foundation for the development of the theoretical model (Fig. 1) for this study to identify the driving and hindering factors regarding internal social media usage intention. The TPB attempts to predict behavior intentions, through three dimensions: attitude, social norms, and perceived behavioral control conditions [1].

Looking at the TPB in an organizational communication media context, an individual's attitude, referred to as acceptance, toward using a technology or media tool can be considered one of the most important determining factors. If employees do not perceive technologies to be advantageous or useful, then employees are less likely to use those technologies [25]. In organizational communication and media usage, an individual's assessment of the quality of the media in question is a huge motivational factor for media usage [36]. Although this factor can be considered key, it is not the only influencing factor for usage intention.

Social norms can just as well have as great an impact and have two different aspects, injunctive and descriptive. Injunctive norms have the intrinsic goal of social approval which is how an individual perceives how others think he/she should behave [16]. An example would be that an employee feels that he/she should use internal social media because he believes his/her direct supervisor expects it of him. If the employee uses these technologies, he/she would be seeking social approval by fulfilling the perceived expectations of his/her supervisor. The other aspect that social norms take on is descriptive norms with the intrinsic goal of correct behavior which is how an individual perceives the behaviors of others $[7,8]$. An example here would be that an employee sees his/her colleagues using internal social media, and therefore believes that this is what is usually done. The employee might decide to use these technologies in order to 'fit in' with colleagues or at least not be an outsider regardless of his/her opinion. These two types of social norms are important for deeper understanding of motivational or hindering factors for behavior intention of internal social media usage. Moreover, it is important to identify which groups within a community have the most influence on social norms. Regarding organizational communication, the groups: colleagues, direct supervisors, and management would appear to be the most important and researched groups [18, 19, 32, 39]. All three of these groups could potentially influence an individual's opinion regarding internal social media usage and thus will be taken into consideration.

The perceived behavior control dimension - "perceived ease or difficulty to perform the behavior" [1, p.188] - is vital in determining an individual's ability of performing a specific behavior. It is possible that even though an individual's attitude and the perceived social norms support usage intention, due to uncontrollable external obstacles, the individual is not able to use the media in question. For example, in a previous study, it was found that in regards to Business-TV usage, irrespective of media acceptance and social pressures, if an employee was not given the opportunity or time to view the program itself, actual media usage could not be carried out [42].

By using the TPB, it is possible to answer the following research question:

RQ1: What possible motivating or hindering factors can influence employees' intention to use internal social media technologies?

Next, the role that organizational communication quality possibly plays in internal social media usage intention will be looked at.

\section{Organizational Communication Quality}

Another important influencing factor for influencing employees' behavior is the reception of relevant and timely information that employees are satisfied with, referred to as an organization's communication quality [5, 12, 21, 22, 29]. The quality of organizational communication during mergers and acquisitions is one example of the important role organizational communication quality plays in influencing employees' behaviors. In such situations, organizations go through many change processes where employees are put under high amounts of stress, often due to poor communication quality [21]. The results of which can lead to low employee performance, employee anxiety, and the loss of talented employees [21, 34]. Timely and relevant information that employees are satisfied with can lessen or eliminate many of these negative effects $[34,37]$. 
Furthermore, organizations' communication quality can have an influence on social norms within the organizations. Social norm perceptions about behaviors are formed based on the exchanged information about those behaviors [20], thus it is possible that the organizational communication quality can have an influence on social norms regarding internal social media technologies, and thereby the usage intention of these technologies. For example, employees that receive relevant and timely information about how others within the organization support and use internal social media technologies are more likely to see the usage of internal social media technologies as being socially acceptable and what is considered to be normal behavior within the organization. Hence, an organization's communication quality could be a potential moderating factor regarding social norms for internal social media usage intention (Fig. 1), making it possible to answer the following research question:

RQ2: What impact does the perceived organizational communication quality have on perceived social norms regarding employees' internal social media usage intention?

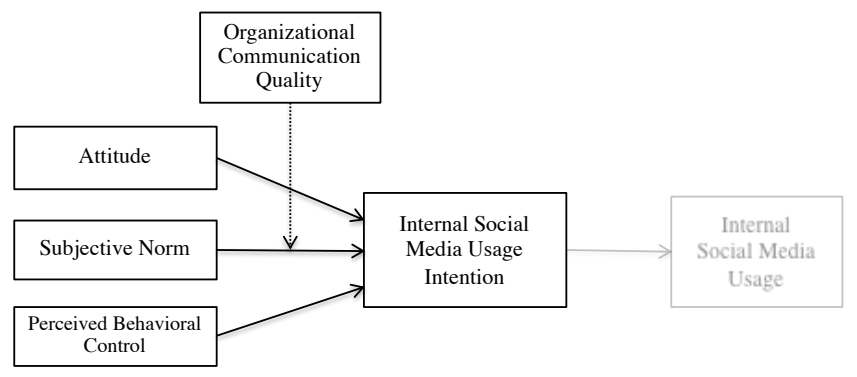

Fig. 1. Theoretical model.

\section{METHOD}

A qualitative study was carried out to address the research questions. The aim was to provide deeper insight as to why employees use and how employees view the usage of internal social media technologies, as well as to give more understanding concerning employees' perception of the organizational communication quality and its impact on social norms regarding internal social media usage intention.

\section{A. Sample}

Purposive sampling with a two-step process was used to recruit organizations [9]. First, organizations were eligible to participate in the study if they had implemented some form of internal social media technologies. Second, employees without a management function were eligible to partake in the study. It was not required that the participants actually use internal social media, just that they had access to them. From September 2016 to May 2019, 346 organizations in Germany, representing a variety of industries, were contacted to participate in this study; from the organizations willing to participate in the study, only six organizations met study requirements. This lack of organizations meeting study requirements shows that many organizations either have not yet implemented internal social media technologies or just in the planning phase of implementing such technologies. Moreover, the lack of organizations meeting study requirements supports the indication that early adopters are now beginning to implement these technologies.
The organizations that participated varied in size from 300 to more than 100,000 employees. The degree to which the organizations had implemented internal social media technologies and the degree to which employees used them varied from test stages to several years' experience. The contact person from each organization determined which employees had access to internal social media and contacted employees directly to partake in the study. Participation was voluntary and not compensated, and participants were guaranteed anonymity. The number of participants per organization varied between two and four depending on availability. In total, 16 participants took part in the study, of which six were female and ten were male.

\section{B. Materials and Process}

The interviews were conducted either in person or via telephone. The interviews lasted between 20 and 45 minutes and were recorded. Questions were developed to include all dimensions of the TPB in regards to internal social media technologies: intentions to use internal social media; attitudes toward internal social media usage; perceived norms regarding internal social media usage among the groups: colleagues, direct superior, and management; and as the behavioral control, the perceived internal social media usage ability. Internal organizational communication quality and transparency was addressed using questions asking participants how the communication within the organization is perceived in regards to colleagues, direct supervisors, and management. As this study's main focus and dependent variable is employees' intention to use internal social media, it is important to note that while 'WhatsApp' was not considered an internal social media tool since it is not behind organizations' firewalls; however, 'WhatsApp' usage repeatedly came up during interviews with all participants. Several participants referred to and described their WhatsApp usage as if it were an internal social media tool.

\section{Data Analysis}

Following transcription, the interview data were coded in multiple cycles and subsequently reorganized and recoded $[14,35]$. In the first cycle, structural codes were developed in order to organize the data into categories along the line of the theoretical model for internal social media usage: usage intention, attitudes, perceived social norms; perceived behavior controls, and organizational communication quality. After which, second cycle coding using pattern coding was begun where subcategories emerged from the data and were developed to refine the categories. For example, whether the participant actually used internal social media technologies or not; positive and negative attitudes towards internal social media including the benefits and problems associated with these technologies; whether or not colleagues, direct supervisors and management supported and used internal social media technologies; facilitating resources available to support internal social media technology usage, such as infrastructure, trainings, and a transition phase during implementation; and the perceived level of organizational communication quality, such as receiving relevant and timely information from colleagues, direct supervisors, and management. After the data was recoded and reorganized, outcomes and findings were then summarized. 


\section{INTERVIEW FINDINGS}

In the following section, the results from the questions regarding usage and usage intention, TPB influencing factors, organizational communication quality, and a summary of the findings are presented.

\section{A. Usage and Usage Intention}

In looking at participants' intention to use internal social media, 14 out of 16 participants said that they intended to use or to increase their usage of internal social media. It is important to note that although both of these participants said that they did not intend to use internal social media, they both gave examples of possible advantages of internal social media usage.

\section{B. TPB Influencing Factors}

TPB influencing factors - employee attitude, social norms, and perceived behavioral control factors - related to internal social media were assessed. Participants were asked questions regarding their individual opinion of internal social media to identify attitudes toward it. The majority of participants were very positive toward internal social media usage; however, there were some problems that were addressed. In exploring employees' attitudes toward the advantages of internal social media, three separate themes emerged: connectivity, innovation, and knowledge management.

Participants viewed that the usage of internal social media would bring about increased connectivity within their organization. They were very positive in being able to use internal social media tools to connect with colleagues and had hopes of connecting more with management. In regards to using internal social media tools to connect with colleagues, one participant made the comment:

Something like an employee portal with different variations where I can get valuable information and also be able to chat with colleagues, for example asking "What are you eating for lunch today?" That would be good. (O5,P8)

In addition to connectivity, the majority of participants viewed the usage of internal social media to bring about fast, innovative, and problem-solving communication. Some keywords participants used to describe the usage of internal social media were, "always at the latest information stand", "current", "innovation", "exchanging ideas", and "faster." Several participants viewed the usage of internal social media to suggest new ideas to be helpful for management to make improvements within the organization.

In addition to better connectivity and innovation, employees believed that the usage of internal social media would improve knowledge management. The majority of participants agreed that internal social media would enable all employees to gather, exchange, and have access to information without information becoming lost or outdated, as one participant described:

Of course, [internal] social media is always up-todate, so you can easily remove things that are no longer valid, then they're gone. (O6,P15)
Although participants tended to view internal social media positively, there were still some concerns with its usage. In looking at employees' attitudes toward the disadvantages of internal social media, four separate themes emerged: irrelevant and distracting information, lack of time to use these technologies, lack of privacy, and lack of information about the personal benefits of using these technologies. Some participants thought that perhaps they might receive too much irrelevant or distracting information which could lead to losing an overview of things. Others were concerned about the time needed to be able to learn something technically new and as well for preparing documents and texts in order to keep information more up-to-date in internal social media. One participant even gave an example of how he/she sometimes feels controlled while using internal social media:

Disadvantages of it are that you are more controlled. For example, when I cannot answer Skype for Business since I am already on the phone, however, it shows that I am online. The person then calls again and asks why I didn't answer since I am online. Then I have to explain myself, even though there is not really a reason for explanation. (O4,P5)

An additional issue that participants addressed was that they felt like there was a lack of information about the personal benefits of using internal social media. One participant made the comment about the launch of internal social media at his/her organization:

There were also internal promoting campaigns for the launch. But this did not lead to everyone using it. Many still ask six years later, 'Why should I use it? How would this benefit me?' (O3,P7)

In summary, attitudes toward internal social media technologies were generally positive with employees and direct supervisors supporting the idea. Participants believed that in using internal social media the organization would see improvements to the speed of communication and the connectivity with not only other employees and direct supervisors, but also potentially with upper management. In addition, participants felt that improvements to organizational processes, project coordination, document access, and knowledge management would be seen. However, participants did address several problems involving the use of internal social media. Participants felt that they and their colleagues did not have enough time or information regarding how to best use these technologies. Additionally, participants felt that they would receive perhaps too much irrelevant information and that they would lose their privacy at work. Regardless of these problems, the majority of participants still viewed the advantages of using these technologies to outweigh the disadvantages.

In identifying social norms concerning internal social media usage, participants were asked various questions which had them describe how they thought the three groups: employees, direct supervisors, and management viewed the usage of internal social media. The majority of participants tended to describe their colleagues' opinions of internal social 
media to be neutral to very positive. There were some concerns and comments made regarding the different generations within organizations.

Additionally, participants felt that the image of internal social media was perceived negatively and not considered professional enough. Regardless of this, none of the participants thought that colleagues would be completely against using internal social media. A few participants made comments about how after colleagues began using internal social media and could see the benefits for themselves, the opinion and support of internal social media improved:

So let's just say, there were people who were not sure if they needed it. But it was still open to use, and in hindsight it turned out to be beneficial to everyone. So everybody thought it was good. (O5,P9)

When participants described their direct supervisors' opinions of internal social media, they remained neutral to positive. Nevertheless, several participants described their direct supervisors as being more critical in observing potential costs and benefits of using internal social media. One participant described his/her boss as follows:

He would look at what makes sense, and not just because it is fancy or wanted from colleagues. He would weigh it well, but is in general very open. (O4,P5)

In contrast to colleagues and direct supervisors, the majority of participants described management's viewpoint toward internal social media as being mainly unsupportive and that management finds that "too much unimportant information is communicated" $(\mathrm{O} 2, \mathrm{P} 4)$. Participants however showed a wish for more support from upper management. One participant went as far as saying that they wished upper management would act more like role models.

The answers regarding social norms clearly show that participants viewed themselves and other employees as being open and positive towards the usage of internal social media, especially after employees gained experience in using these technologies. However, employees are looking for upper management to show the same kind of support.

Finally, the third dimension - behavioral control factors was looked at. Participants were asked questions regarding their ability to use internal social media which could influence their usage intention of these technologies, such as not having the necessary technical resources. All participants felt that they would be able to easily use internal social media and confirmed that their organization had held a transition period for using and learning the internal social media tools. Most interesting of the behavioral control questions were that participants felt confident in using the software tools independently. Nonetheless, when asked if they would like training courses for how to use internal social media, the majority of participants specifically stated that they would like to have courses to demonstrate how it could be used for their benefit, as one participant stated: "Definitely. Here it is possible to show everyone [how it can be used]" (O6,P15).

Overall, participants did not perceive there to be any difficulties in using internal social media. That being said, participants still felt that more information about the use and benefits of internal social media should be made available through training courses.

\section{Organizational Communication Quality}

Organizational communication quality was considered to moderate social norms in regards to internal social media usage intention. Participants were asked questions on their perception of the communication quality with their colleagues, direct supervisors, and management. In regards to participants' perception of the communication quality with their colleagues and direct supervisors, employees mainly viewed communication quality to be high:

We have group leaders and team leaders that always have their door open. That means that when there is something you can just walk over and see if they have time to quickly speak with you. $(\mathrm{O} 1, \mathrm{P} 1)$

In contrast, many participants viewed the communication quality with management to be poor. Several participants made reference to a lack of information being communicated from management and/or expressed a sense of confusion with the information that is communicated:

I wish that things would be discussed at a company level. It is often so that things are only discussed and communicated within small circles. I find that to be a shame. $(\mathrm{O} 2, \mathrm{P} 4)$

Since the information that is received is incomplete, we try to understand it by means of the grapevine and ask colleagues, 'Say, how did you understand that?' $(\mathrm{O} 5, \mathrm{P} 8)$

Participants perceived their colleagues and direct supervisors as having high communication quality; however, management was seen as having low communication quality.

\section{DISCUSSION}

In the following, the findings in regards to the research questions will be addressed, followed by theoretical and practical implications, and finally study limitations and recommendations for future research.

The main purpose of the study was to gather information rich data to give in-depth insights as to why employees use and how employees view the usage of internal social media technologies. In answering the first research question: "Why do employees intend to use internal social media technologies?", the study's findings offer interesting insight especially in regards to potential barriers for internal social media usage. The main reason for participants' acceptance and support of internal social media technologies was that they felt that in using these technologies it would allow them to become more efficient in their jobs, specifically concerning: improvements to organizational processes; project coordination; document access; knowledge management; and faster and better communication. In addition to these individual motivating factors, employees see internal social media as something positive and felt that their 
colleagues and direct supervisor would be supportive of or at least not against using internal social media. Finally in regards to behavioral control factors, participants felt that they would have the technological resources and that there would be minimal problems in independently using internal social media technologies.

On the other hand, this study has been able to identify some potential barriers which might hinder employees from using internal social media technologies. First of all, participants felt that there was a lack of information about the personal benefits of using internal social media technologies and that they did not have the appropriate time to not only use but learn to use these technologies. In addition to this, participants also stated that they and their colleagues find internal social media to often have a negative image. These technologies are compared to other general social media platforms which are considered to be distracting and full of irrelevant information. It was also felt that older generations were not as accepting as younger generations and that management is unsupportive regarding the usage of these technologies. Finally, there was a strong wish for trainings that would show what specific benefits using internal social media would bring to everyday work.

In order to answer the second research question, "What relationship does the organizational communication quality have with social norms regarding internal social media usage intention?", participants' perception of the communication quality with colleagues, direct supervisors and management were compared with the usage support and behavior of internal social media among those groups. Here, a certain trend was able to be identified. Participants perceived the organizational communication quality among colleagues and direct supervisors to be satisfactory and felt that social norm pressures from colleagues and direct supervisors to be mainly positive and supportive in regards to internal social media usage. Whereas, participants perceived the management communication quality to be unsatisfactory and as well felt that management gives the impression of being unsupportive in regards to internal social media usage. This would also appear to have a unique impact on the above mentioned barriers in that when employees are unsatisfied with the communication quality and employees feel that there is in general a lack of information being communicated, then it is plausible that employees feel that they are not receiving enough information about how these new technologies can benefit them personally. On the other hand, when employees feel that they are satisfied with the communication quality with colleagues and their direct supervisors, then it is likely that these benefits are openly discussed amongst themselves. Based on these findings and previous research showing that organizational communication quality can influence employees' behaviors, this study gives first indications that it can influence media and technology usage. By not considering an organization's communication quality, the motivating and hindering factors for usage intention of internal social media technologies could be underestimated. Hence, this study offers a unique extension to the TPB by including the perceived organizational communication quality and what effects it could have on internal social media usage.

\section{LIMITATIONS AND RECOMMENDATIONS}

This study is of course not without its limitations. The implementation of internal social media technologies in organizations is relatively new. Many organizations have just begun to consider using these technologies. Although many organizations were asked to participate, many were either in the planning phase of implementing or completely lacking internal social media technologies. Thus, it was difficult to find organizations that could participate in the study. Therefore, it was strived to have organizations with various sizes from various industries. By doing this, it was possible to reduce any bias that might occur which would give a more diverse and broader understanding of the study outcomes.

After having qualitatively explored why employees use and how employees view the usage of internal social media technologies, it is recommended that future research should examine the usage intention of internal social media technologies in organizations at a quantitative level.

As employees' attitude toward internal social media and their perception of colleagues' and direct supervisors' usage support and usage behavior were positive, organizations should foster an environment that is supportive of internal social media. Support and usage of these technologies among management could be seen as a way to reduce disconnect and improve communication and relations between employees and management. As it seems that the level of organizational communication quality can influence the social norms regarding internal social media usage and thereby the usage intention of these technologies, organizations should promote the exchange of relevant and timely communication with and among all internal stakeholders. Moreover, organizations should offer training and information sessions to employees showing and explaining the uses and benefits of internal social media. Thus, organizations can possibly overcome some of the potential barriers that have been discussed. Through such training and information sessions, employees can gain a better understanding of how it could be helpful for them personally and as well to improve the negative image that is often confused with social media tools used by the public. These sessions would allow for organizations to explain the difference and promote the usage of these internal tools.

Furthermore, as employees are showing a desire and need for such technologies at work, organizations must consider the ramifications that might result from these tools not being offered. If employees are not given such tools for their work processes, they will actively search for alternatives which are more than likely not within a secured network. While the majority of such converse through external tools, such as 'WhatsApp', is more than likely harmless and employees usually have good intentions, it is possible that employees are sharing company sensitive information without truly realizing potential consequences. With this in mind, every organization will need to carefully consider if the usage of 'WhatsApp' or similar tools could possibly be considered critical. If so, then they should consider implementing an alternative that is located behind their firewall, or else risk a potential data security breach. 


\section{CONCLUSION}

The findings of this study indicate that most employees have a need for internal social media technologies within their organization. There are strong motivational factors which support employees' usage of internal social media, and thus the benefits that internal social media brings to organizations. On the other hand, there are also hindering factors which discourage employees' usage of these technologies that must be taken into consideration.

If both motivating and hindering factors are not considered, then organizations risk not only the loss of the potential benefits of internal social media, but also wasted resources from implementing these technologies. Furthermore, if internal social media technologies are not offered by the organization, then employees will seek external alternatives to use for work related activities without potential security issues being considered. Thus, as social media continues to become an integral part of our private lives, organizations will need to adapt to meet the changing needs of employees to be able to use internal social media technologies in organizations.

\section{ACKNOWLEDGMENT}

Kristen Werling thanks Professor Dr. Michaela Maier and Berend Barkela for their helpful feedback and input for this study and paper.

\section{REFERENCES}

[1] I. Ajzen, "The theory of planned behavior," Organizational Behavior and Human Decision Processes, vol. 50, no. 2, pp. 179-211, 1991.

[2] M. Badea, "Social media and organizational communication," Procedia-Social and Behavioral Sciences, vol. 149, pp. 70-75, 2014.

[3] N. Behringer and K. Sassenberg, "Introducing social media for knowledge management: Determinants of employees' intentions to adopt new tools," Computers in Human Behavior, vol. 48, pp. 290-296, 2015.

[4] R. Beck, I. Pahlke and C. Seebach, "Knowledge exchange and symbolic action in social media-enabled electronic networks of practice: A multilevel perspective on knowledge seekers and contributors," MIS Quarterly, vol. 38, no. 4, pp. 1245-1270, 2014.

[5] S. H. J. Chan and H. Y. I. Lai, "Understanding the link between communication satisfaction, perceived justice and organizational citizenship behavior," Journal of Business Research, vol. 70, pp. 214223, 2017.

[6] C. M. Cheung, P.-Y. Chiu and M. K. Lee, "Online social networks: Why do students use facebook?" Computers in Human Behavior, vol. 27, no. 4, pp. 1337-1343, 2011.

[7] R. B. Cialdini, R. R. Reno and C. A. Kallgren, "A focus theory of normative conduct: recycling the concept of norms to reduce littering in public places," Journal of Personality and Social Psychology, vol. 58, no. 6, pp. 1015-1026, 1990 .

[8] R. B. Cialdini and M. R. Trost, "Social influence: Social norms, conformity and compliance," in The Handbook of Social Psychology D. T. Gilbert, S. T. Fiske and G. Lindzey Eds. New York, NY: McGraw-Hill, 1998, pp. 151-192.

[9] I. Etikan, S. A. Musa and R. S. Alkassim, "Comparison of convenience sampling and purposive sampling," American Journal of Theoretical and Applied Statistics, vol. 5, no. 1, pp. 1-4, 2016.

[10] N. Eyrich, M. L. Padman and K. D. Sweetser, "PR practitioners' use of social media tools and communication technology," Public Relations Review, vol. 34, no. 4, pp. 412-414, 2008.

[11] GlobalWebIndex. "Global Web Index Social Report," 2018. Retrieved from https://www.globalwebindex.com/reports/social

[12] J. Gochhayat, V. N. Giri and D. Suar "Influence of organizational culture on organizational effectiveness: The mediating role of organizational communication," Global Business Review, vol. 18, no. 3, pp. 691-702, 2017.
[13] T. Grosser, V. Kidwell and G. Labianca, "Hearing it through the grapevine: Positive and negative workplace gossip," Organizational Dynamics, vol. 41, pp. 52-61, 2012.

[14] I. Hay Qualitative research methods in human geography 4th ed. Canada: Oxford University Press, 2016.

[15] K. Hutter, J. Hautz, S. Dennhardt and J. Füller, "The impact of user interactions in social media on brand awareness and purchase intention: the case of MINI on Facebook," Journal of Product \& Brand Management, vol. 22, no. 5/6, pp. 342-351, 2013.

[16] R. P. Jacobson, C. R. Mortensen and R. B. Cialdini, "Bodies obliged and unbound: Differentiated response tendencies for injunctive and descriptive social norms," Journal of Personality and Social Psychology, vol. 100, no. 3, pp. 433-448, 2011.

[17] J. D. Johnson, W. A. Donohue, C. K. Atkin and S. Johnson, "Differences between formal and informal communication channels," The Journal of Business Communication, vol. 31, no. 2, pp. 111-122, 1994.

[18] N. S. A. E. Kandlousi, A. J. Ali and A. Abdollahi, "Organizational citizenship behavior in concern of communication satisfaction: The role of the formal and informal communication," International Journal of Business and Management, vol. 5, no. 10, pp. 51-61, 2010.

[19] E. Karanges, K. Johnston, A. Beatson and I. Lings, "The influence of internal communication on employee engagement: A pilot study," Public Relations Review, vol. 41, no. 1, pp. 129-131, 2015.

[20] K. Keizer and P. W. Schultz, "Social Norms and Pro-Environmental Behaviour," in Environmental psychology: An introduction, 2nd ed., L. Steg \& J. de Groot Eds. Hoboken, NJ: John Wiley \& Son Ltd., 2019, pp. $179-188$.

[21] H. Kim, "Change communication and the use of anonymous social media at work," Corporate Communications: An International Journal, vol. 24, no. 3, pp. 410-424, 2019.

[22] Y. Kim, M. Kang, E. Lee and S.-U. Yang, "Exploring crisis communication in the internal context of an organization: Examining moderated and mediated effects of employee-organization relationships on crisis outcomes," Public Relations Review, vol. 45, no. 3, 101777, 2019 .

[23] P. M. Leonardi, "Ambient awareness and knowledge acquisition: using social media to learn 'who knows what' and "who knows whom'," MIS Quarterly, vol. 39, no. 4, pp. 747-762, 2015.

[24] P. M. Leonardi, "Social media, knowledge sharing, and innovation: Toward a theory of communication visibility," Information Systems Research, vol. 25, no. 4, pp. 796-816, 2014.

[25] T.-C. Lin and S. Lin, "A tripartite acceptance model for Enterprise 2.0 systems," Quarterly Review of Business Disciplines, vol. 6, no. 1, pp. 59-78, 2019.

[26] X. Lin, P. R. Spence, T. L. Sellnow and K. A. Lachlan, "Crisis communication, learning and responding: Best practices in social media," Computers in Human Behavior, vol. 65, pp. 601-605, 2016.

[27] L. R. Men, "Strategic internal communication: Transformational leadership, communication channels, and employee satisfaction," Management Communication Quarterly, vol. 28, no. 2, pp. 264-284, 2014.

[28] L. R. Men, "The internal communication role of the chief executive officer: Communication channels, style, and effectiveness," Public Relations Review, vol. 41, no. 4, pp. 461-471, 2015.

[29] L. R. Men and C. A. Yue, "Creating a positive emotional culture: Effect of internal communication and impact on employee supportive behaviors," Public Relations Review, vol. 45, no. 3, 101764, 2019.

[30] R. Miller and N. Lammas, "Social media and its implications for viral marketing," Asia Pacific Public Relations Journal, vol. 11, no. 1, pp. $1-9,2010$.

[31] S. A. Moorhead, D. E. Hazlett, L. Harrison, J. K. Carroll, A. Irwin and C. Hoving, "A new dimension of health care: systematic review of the uses, benefits, and limitations of social media for health communication," Journal of Medical Internet Research, vol. 15, no. 4, 2013.

[32] P. Neves and R. Eisenberger, "Management communication and employee performance: The contribution of perceived organizational support," Human Performance, vol. 25, no. 5, pp. 452-464, 2012.

[33] D. J. Pauleen and P. Yoong, "Facilitating virtual team relationships via Internet and conventional communication channels," Internet Research, vol. 11, no. 3, pp. 190-202, 2001.

[34] R. Raina and D. B. Roebuck, "Exploring Cultural Influence on Managerial Communication in Relationship to Job Satisfaction, Organizational Commitment, and the Employees' Propensity to Leave in the Insurance Sector of India," International Journal of Business Communication, vol. 53, no. 1, pp. 97-130, 2016.

[35] J. Saldaña, The coding manual for qualitative researchers, $3 \mathrm{rd}$ ed. London: Sage Publications Ltd., 2015. 
[36] C. Smith and J. A. Wiid, "The characteristics of e-newsletters in predicting higher education institution employees' usage," Communitas, vol. 24, pp. 1-17, 2019.

[37] C. L. ter Hoeven, C. Stohl, P. Leonardi and M. Stohl, "Assessing Organizational Information Visibility: Development and Validation of the Information Visibility Scale," Communication Research, $0093650219877093,2019$.

[38] R. Thackeray, B. L. Neiger, C. L. Hanson and J. F. McKenzie, "Enhancing promotional strategies within social marketing programs: use of Web 2.0 social media," Health Promotion Practice, vol. 9, no. 4, pp. 338-343, 2008.

[39] M. van Vuuren, M. D. de Jong and E. R. Seydel, "Direct and indirect effects of supervisor communication on organizational commitment," Corporate Communications, vol. 12, no. 2, pp. 116-128, 2007.

[40] V. Vuori and J. Okkonen, "Knowledge sharing motivational factors of using an intra-organizational social media platform," Journal of Knowledge Management, vol. 16, no. 4, pp. 592-603, 2012.

[41] M. Welch and P. R. Jackson, "Rethinking internal communication: a stakeholder approach," Corporate Communications, vol. 12, no. 2, pp. 177-198, 2007.

[42] K. Werling, B. Barkela, and A. Fiedler, "Leading by example and expectation: How managers can positively influence employees' usage of internal communication media," presented at the International Academy of Business Disciplines $31^{\text {st }}$ Annual Conference, Jacksonville, FL, April 3-5, 2019.

[43] S. Wigley and W. Zhang, "A study of PR practitioners' use of social media in crisis planning," Public Relations Journal, vol. 5, no. 3, pp. 1-16, 2011.

[44] X. Zhang, Y. Gao, X. Yan, P. O. de Pablos, Y. Sun and X. Cao, "From e-learning to social-learning: Mapping development of studies on social media-supported knowledge management," Computers in Human Behavior, vol. 51, pp. 803-811, 2015.

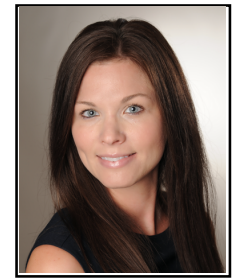

Kristen Werling (born in Pensacola, FL USA) has a Master of Business Administration and is a $\mathrm{PhD}$ candidate at the Institute for Communication Psychology and Media Education at the University of Koblenz-Landau. Her research focus is on internal organizational communication and psychology, organizational communication quality, and the implementation and usage of traditional communication and social media within organizations. 